\section{An application of Earned Value Management (EVM) with Monte Carlo simulation in engineering project management}

\section{Uma aplicação do Earned Value Management (EVM) com simulação Monte Carlo em projetos de engenharia}

\author{
Felipe Kahan Bonato ${ }^{1}$ (D) \\ Andrei Aparecido de Albuquerque ${ }^{1}$ (D) \\ Michel Augusto Santana da Paixão² (D)
}

\section{GESTÃO PRODỨĈ̃O}

ISSN 0104-530X (Print) ISSN 1806-9649 (Online)

\begin{abstract}
How to cite: Bonato, F. K., Albuquerque, A. A., \& Paixão, M. A. S. An application of Earned Value Management (EVM) with Monte Carlo simulation in engineering project management. Gestão \& Produção, $26(3)$, e4641. https://doi.org/10.1590/0104-530X4641-19
\end{abstract}

\begin{abstract}
The fast changes in the Market make companies increasingly focus on project structures. A project differs from a routine activity because it is unique and must be managed and structured to provide expected benefits at no greater cost than anticipated. Therefore, it must be planned and controlled by identifying the deviations between the planned and the accomplished. In order to provide this monitoring, Earned Value Management (EVM) has been increasing accepted. In addition to showing indicators of progress, EVM can be used to forecast the project's final costs through simulated scenarios. This work aims to integrate and apply EVM with Monte Carlo simulation to predict the final costs of three detailed engineering projects, evaluating the performance of the model and the projects, in each specific case study. The results of the three projects simulations were evaluated in a qualitative and comparative way, showing that the integration between the tools generates useful forecasts for project management.
\end{abstract}

Keywords: EVM; Monte Carlo simulation; Project management; Performance measurement.

Resumo: As rápidas alterações no mercado, faz que as empresas, cada vez mais, se orientem através de estruturas de projetos. Assim, um projeto difere de uma atividade rotineira pois é único, sendo gerenciado, e proporcionando beneficios esperados sem custos maiores que o previsto. Logo, deve-se planejá-lo e controlá-lo identificando os desvios entre o planejado e o realizado. Para esse acompanhamento, o Earned Value Management (EVM) vem mostrando crescente aceitação. Além de mostrar indicadores sobre o avanço realizado, o EVM pode ser usado para antever os custos finais do projeto, através de cenários simulados. Este trabalho tem como objetivo integrar e aplicar o EVM com a simulação de Monte Carlo para prever os custos finais de três projetos de engenharia de detalhamento, avaliando o desempenho do modelo e dos projetos, em uma pesquisa-ação de natureza aplicada. Os resultados das simulações dos três projetos foram avaliados de forma qualitativa e comparativa mostrando que a integração entre as ferramentas gera previsões úteis à gestão de projetos.

Palavras-chave: EVM; Simulação Monte Carlo; Gerenciamento de projetos; Medição de desempenho.

\section{Introduction}

After a recent expansion of the Brazilian GDP between 2004-2008 and 2010-2013, it was also observed that the engineering and construction companies expanded their projects disorderly. Subsequently, however, there were credit constraints and high indebtedness, making these companies face a reality, in demanding greater discipline in their choice of projects and greater control in their execution with low costs, term and quality. Therefore, there has been an evolution of project monitoring practices in the civil engineering sector (Silva et al., 2014; Berssaneti et al., 2014).

\footnotetext{
${ }^{1}$ Departamento de Engenharia de Produção, Universidade Federal de são Carlos - UFSCar, Rodovia Washington Luís, SP-310, Km 235, CEP 13565-905, São Carlos, SP, Brasil, e-mail: fkbonato@gmail.com; andrei@dep.ufscar.br

${ }^{2}$ Departamento de Economia, Universidade Estadual do Norte do Paraná - UENP, Rodovia PR 160, Km 0, CEP 86300-000, Cornélio Procópio, PR, Brasil, e-mail: michelfeiradesantana@gmail.com
}

Received Feb. 12,18 - Accepted May. 02,18

Financial support: None. 
Thus, project management methods and tools are needed (Prado, 2003). According to Berssaneti et al. (2014), term, cost and quality are criterions of a project success. In this way, there are projects that need to be managed and evaluated periodically (Giacometti et al., 2007). In this context, Earned Value Management (EVM) offers a certain precision in terms and costs in any phase of the project, showing discrepancies between planned and accomplished (Oliveira, 2003). According to Kim et al. (2003), Giacometti et al. (2007) and Colin \& Vanhoucke (2015), EVM use is increasing, so its usefulness has improved.

EVM can be useful in predicting and controlling a project in the future. In order to do this, the estimated cost of the project can be calculated countless times, considering scenarios that generate a distribution of probabilities helping in the decisions (Baena, 2010). Also, according to Colin \& Vanhoucke (2015), EVM provides performance indicators to compare the planned and the executed project in terms of cost.

The objective of this work is to apply EVM and Monte Carlo simulation to predict the final costs of three detailed engineering projects, analyzing the performance and impacts brought by this combination of methodologies. Thus, this paper will help to determine the relevance of these tools use for forecasting costs in detailed engineering projects. In this way, the produced data and discussions were analyzed and reported in order to examine the performances of these simulations.

\section{Bibliographical review}

\subsection{Project management}

This section aims to review the literature, present the state of the art research in project management, as well as defining the initial concepts.

According to Kerkhove \& Vanhoucke (2017), project management and monitoring requires the use of decision-making tools with some precision. For Kerkhove \& Vanhoucke (2017), these models provide information for better management without the need for a myriad of unnecessary data.

According to PMI (2013, p. 4), a project is "[...] a temporary effort undertaken to create a unique product, service or result [...]". A project differs from continuous work by having a beginning and an end, driven by an organization designed to execute it until its completion (Henriques, 2008).

For Dinsmore \& Rocha (2012), one should align the set of projects developed with the objective of each one, interconnecting them with the creation of desired value. So, in addition to planning and execution, one must consider the context, strategies, priorities and resources that subsidize or limit each project.

From this alignment and with the objective of the project, it is possible to plan and monitor the project, achieving the success defined by the stakeholders (Kerzner, 2014). For Kerzner (2014), the main challenge is the management of complex activities, which are increasingly bigger and more complex, requiring planning and control tools. Then, there are numerous methods of support for project management.

According to NBR ISO 21500 standard of ABNT (2012), project management is the application of necessary methods in the execution of a project. To PMI (2013), this is followed by five groups of processes: initiation, planning, execution, control and finalization, which may also contain sub processes. The phases of planning starts before the project (Slack et al., 2007).

To Kerkhove \& Vanhoucke (2017), the control phase of a project must be monitored, observing its progress, taking necessary action if something goes unplanned, using quantitative techniques that assist managers in this control. Similarly, tracking the timeline means monitoring the course and progress of the project, determining which factors are on schedule. Thus, cost control has a greater systematization, since it involves financial resources (PMI, 2013).

For better control, PMI (2013), Slack et al. (2007) and the National Defense Industrial Association - NDIA (2015) suggest EVM. PMI (2013) defines EVM as the widely- used method to measure performance, integrating costs, scope and timeline, assisting in the management, evaluation and measurement of project performance. To Slack et al. (2007), this method evaluates the project through time and cost, measuring its progress in terms of what has been accomplished. NDIA (2015) adds that EVM allows the extrapolation of performance trend lines, anticipating decision making. However, it is necessary to include EVM in an integrated management system with efficient processes and appropriate tools.

\subsection{Earned Value Management (EVM)}

Mattos (2010) describes EVM as a system that integrates actual collected and planned data that are relative to schedule and costs.

Rovai \& Toledo (2002) highlight EVM's efficiency in showing the progress of the project already in its initial phase, signaling its status, even with only $10 \%$ to $15 \%$ completed. In addition to that, EVM evaluates compliance with the schedule in the context of the planned schedule, under the approved budget, observing scope deviations, controlling the scope-time-cost tripod. For PMI (2013), EVM depends on an integrated baseline in which performance can be measured throughout the project. Besides this, EVM can be applied to all projects in any industry by monitoring the three key dimensions for each control account. 
According to Henriques (2008), EVM allows to evaluate performance about what was planned, improving communication with stakeholders, based on quantitative indicators, elevating the available information to the work team impersonally. Thus, it is sought to establish forecasts and trends and to compare performance among several projects.

In order to implement EVM, Meredith, Mantel $\&$ Shafer (2014) first emphasize the importance of the scope, because a lack of definition makes its use unfeasible since the standard of work to be performed is too general. Furthermore, it is necessary to carry out time and cost planning, set in the so-called baseline in terms of schedule and budget (Vargas, 2004). Raby (2000) suggests eight steps for applying the EVM, in order to calculate their indexes, thus analyzing the information and preparing the reports.

As for Willems \& Vanhoucke (2015), there are new potential areas of research on project control, within EVM scope, which are: i) growing attention to the stochastic nature of projects; ii) growth in the methodological use of simulations and historical data series for validation of a project; iii) expansion of integrated models focused on time and cost, as well as on other factors, such as quality and sustainability, and; iv) development and validation of corrective actions and procedures.

About the variables and indicators related to EVM, the papers of Vargas (2004), Henriques (2008), Doskočil (2015), Willems \& Vanhoucke (2015), Chen et al. (2016), Acebes et al. (2015) serve as a references.

\subsubsection{Definition of variables}

This section aims to define the main variables involved in EVM, as described in the previous section. In this section, CPI performance is also presented within the specialized literature.

Starting with Budgeted Cost of Work Scheduled (BCWS), which consists of the sum of the approved costs for the tasks if executed as planned, that is, during the expected time for its execution. It indicates the overall cost (cumulative) of the project in the baseline, allowing the forecast of the expenses until a certain date. Also called Planned Value (PV), it serves as a starting point to evaluate the current performance of the project. The total accumulated is called Budget at Completion (BAC), consisting of the full budget.

Then, there is the Budgeted Cost of Work Performed (BCWP), which refers to the amount of costs originally budgeted for the amount of work performed in a period of time. Also called Earned Value $(\mathrm{EV})$, it is determined from the percentage of the tasks completed in a value earned through work.

The Cost of Work Performed (ACWP), is defined as the quantification of effective costs in performing the tasks already completed up to a given moment.
Also called Actual Cost (AC), it represents the effective cost of the task from the actual work data, from the beginning to the state date, i.e., they are accumulated values.

There are different ways to measure BCWP, according to Fleming \& Koppelman (2010), which are milestones with weights, fixed formulas, equivalent units, and percentages. This work will make use of the latter, which has as a premise the attribution of certain percentages to the extent that the work is performed.

Henriques (2008) states that based on the three variables listed (BCWS, BCWP and ACWP), there are indicators that allow for the assessment of the state and performance of the project at any point.

The Cost Variance (CV) consists of costs deviation, measuring the difference between the expected cost for the quantity of work already executed and the actual cost effectively required for such execution, according to Equation 1.

$$
C V=B C W P-A C W P
$$

Schedule Variance (SV) is defined as the deviation of deadlines. It measures the difference between the amount of work already performed and the one that was expected to be executed, for the same state date, according to Equation 2.

$$
s v=B C W P-B C W S
$$

Cost Performance Index (CPI) is the level of cost performance. It lists the expected costs for the amount of work already performed and the actual costs incurred in its execution. Whenever this ratio is higher than a unit, it means that the cost of the work already done is lower than what was planned. Equation 3 shows the calculation of the CPI.

$$
C P I=B C W P / A C W P
$$

Schedule Performance Index (SPI) consists of a performance index of deadlines. It is related to the amount of work performed and the amount expected to run on the same period of time. Whenever this indicator is greater than a unit, it means that the project is ahead of schedule. Equation 4 shows the calculation of SPI.

$$
S P I=B C W P / B C W S
$$

Estimated at Completion (EAC), consists of the estimate of completion, representing an estimate for the final cost of the project, if the performance of deadlines and costs, evidenced on the date of the state in which such forecast is made, it should be maintained. This estimate makes it possible to detect and quantify the deviations from what was planned and to warn about the need to take corrective measures. Equation 5 shows the calculation of the EAC.

$$
E A C=A C W P+(B A C-B C W P) / C P I
$$


In general, it is observed that the CPI does not vary much throughout the project. For Fleming \& Koppelman (2010), CPI stabilizes when the project reaches $20 \%$ progress, where the variation does not exceed $10 \%$ of the value of the indicator, also observed in absolute terms (Payne, 1990; Christensen \& Payne, 1992; Zwikael et al., 2000). However, CPI stabilization can occur with a higher rate of progress, as Payne (1990) found a CPI stabilization after the project reached $50 \%$ progress. Henderson \& Zwikael (2008) observed that the CPI stabilized after the project reached $60 \%$ progress.

The general CPI stabilization rule is valid for larger projects, while in smaller projects the CPI does not stabilize quickly (Payne, 1990; Henderson \& Zwikael, 2008; Lipke et al., 2009; Lipke, 2011; Koning \& Vanhoucke, 2016). This may indicate the application of EVM with Monte Carlo simulation in smaller projects in order to obtain more realistic values in the projection of final costs.

\subsection{Monte Carlo simulation}

Monte Carlo simulation originated in the post-war 1940s, initially proposed by Stanislaw Ulam, which aimed to analyze the odds of certain plays of a card. However, in performing these calculations, Ulam realized that he spent a lot of time on his execution, noting that it would be more practical to perform a large number of moves, analyzing the occurrence of the results and their probabilities (Breitman, 2012).

At the same time, computer research was developing, with the first computer known as Electronic Numerical Integrator and Computer (ENIAC). This allowed the use of Monte Carlo method, being used in diffusion of the effects of nuclear weapons simulations (Sobol', 1994).

Thus, as computational technology progressed, a myriad of Monte Carlo simulation jobs were observed in several fields of science such as physics, mathematics, biology, finance, economics, project management, in areas where risk and uncertainties exist (Metropolis \& Ulam, 1949; Martins, 2006).

This method consists of generating random numbers for a given variable, in order to simulate possible scenarios of a model, following a given probability distribution (Cardoso \& Amaral, 2000; Schuyler, 2016). Therefore, the simulation of these values is done through samplings based on a probability density function representing the probabilities of a random variable established through the use of a distribution function, satisfying a chosen probability distribution. Thus, a number of random numbers are generated, which will be used for a given analysis (Brandão et al., 2016).

For Acebes et al. (2015), the use of Monte Carlo simulation is associated with the nature of the risk present in a project. Thus, assuming the stochastic nature of a project, its use proves adequate in cost analysis and projections, improving project management. The use of Monte Carlo simulation is justified to predict the final costs present at the center of EVM. A good start is to work with two final cost values. If, with $15 \%$ of the project completed, the estimated value is above the projected, it is necessary to identify the reasons for the deviations so that the project does not present higher costs in its conclusion. With the correct use of Monte Carlo it is hoped to obtain a more reliable interval of predictions in order to have a more effective control over the mentioned deviations.

For Acebes et al. (2014), Monte Carlo simulation with EVM provides greater control in project management under situations of uncertainty and risk. Thus, the combination of both methodologies helps to know the variability of the project throughout its execution (Acebes et al., 2014). In the proposed model, the input data is the triangular probability functions of the six engineering areas (Grey, 1995; Vose, 2008; Kim, 2016).

The use of Monte Carlo simulation has its advantage in considering all possible combinations with numerous scenarios, generating a probability distribution of results (Cardoso \& Amaral, 2000; Schuyler, 2016). The simulation can be applied to schedules, costs or other indicators and has the advantage of generating a satisfactory result with a simplified model. Thus, we created possible results for the project data, with multiple scenarios, obtaining the distribution of the final costs of detailed engineering (Vargas, 2004).

\section{Research method}

EVM was applied with Monte Carlo simulation to predict, month by month, the probable final cost of a project (Acebes et al., 2014, 2015; Batselier \& Vanhoucke, 2015; Kim, 2016). A qualitative, complementary approach was also used to analyze the factors that influenced the variation of these monthly forecasts and to observe the particularities of each one of the projects in which the technique was applied, and the case study procedure was selected as the most adequate (Yin, 2001)

\subsection{Data collection}

Three detailing projects (A, B and C) were conducted by an engineering project company that was contracted to design expansions of sugar and alcohol plants located in the state of São Paulo. The engineering company had recent experience in the industry, but its activities did not have an exclusive focus on that sector or client. Projects A and C refer to the same plant, although of totally independent progress, while project $B$ refers to another industrial unit. The same teams were used for the three projects, with projects $\mathrm{A}$ and $\mathrm{B}$ starting simultaneously and $\mathrm{C}$ with starting 
later. Project B was the first to be completed with $\mathrm{A}$ and $\mathrm{C}$ being finalized simultaneously at a later time. The three projects, which lasted less than a year, were developed in parallel.

In the company where the study was carried out, each of the projects related to industrial plants can be divided between the engineering and the field. The engineering is subdivided into basic (or conceptual) design, executive (or detailing), construction assistance and as built. Figure 1 shows the succession between the engineering phases and the field.

The basic project is elaborated on the concept of the project, dealing with the macro definitions, as the main processes, capacities and requirements. In the detailing, all the necessary engineering is performed so that a plant can operate without undesired stops. More than the macro definitions, all other requirements and integrations required are detailed. In the assistance to the work, the engineering teams support the construction and assembly of the project, leading to its execution. The final phase of as built is the stage in which adjustments are made so that the issued documents in the detailing contemplate small changes that were necessary in the execution of the work, then, reflecting, what was actually constructed. For this research, only the detailing stage was studied.

The engineering services are separated according to the specialties in the company that provides these services where the study was carried out (Figure 2), which represents the summarized Project Analytical Structure (PAS).
The Processes area is responsible for mass and energy balances, as well as all processes required for production. The Mechanics is responsible for the necessary equipment and the Civil area is responsible for the support of these and for studies of hydraulics and architecture. The Electric designs the electrical network to supply the equipment, while the instruments are the responsibility of the Instrumentation area, which designs the plant automation system. The Piping area connects the processes as specified. These are the six areas that are monitored through EVM and make up the cost of the detailing project. Each of these specialties is represented by a team of engineers, each with its area coordinator who reports to the Project Manager, who is responsible for the scope of Total Engineering. Each area is responsible for one part of the total detailing project, and must manage its scope, time frame, and costs. Therefore, there must be an intense exchange of information so that the decisions of one area do not negatively impact the work of another.

The case study began with some unstructured interviews based on Barbosa \& Lopes (2016), with supervisors of the planning areas of the company that provide the engineering services. This process served to identify the need to better structure EVM tool and define what costs or hours should actually be considered in the baseline and EVM metrics. It was defined that only the employees' and third parties' salary costs would be used.

Next, we accessed the tables with EVM indicators generated by the teams involved in the three engineering

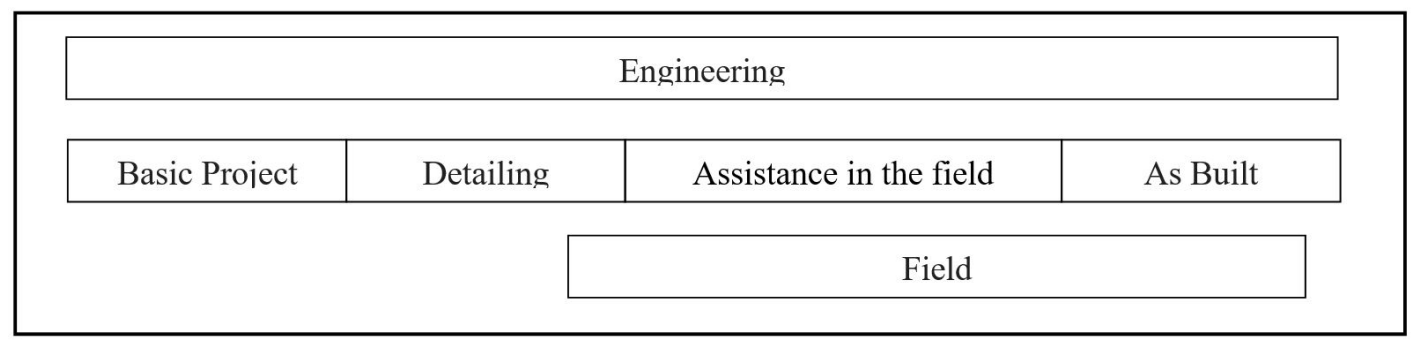

Figure 1. Phases of an industrial plant project.

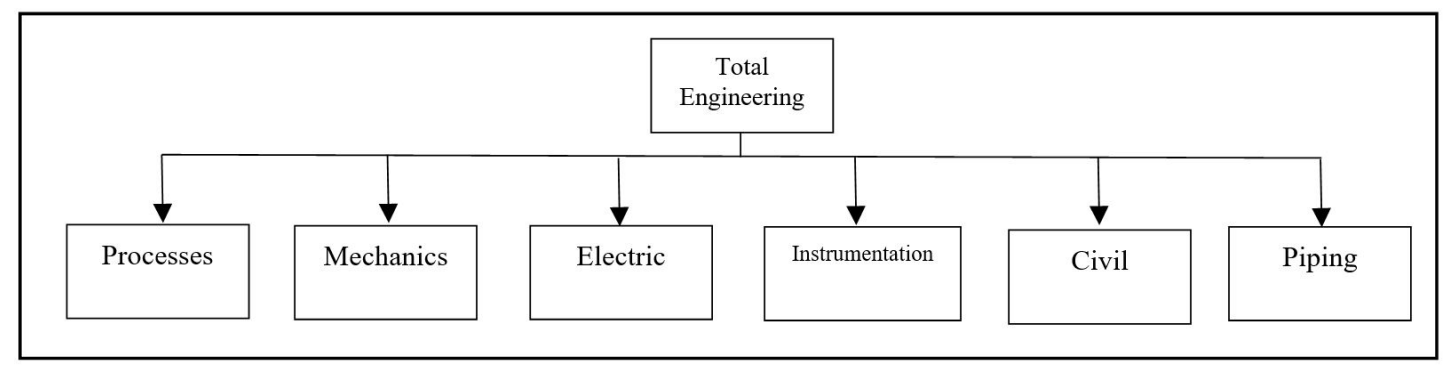

Figure 2. EAP used in EVM of the three projects studied. 
projects analyzed, creating the simulation model, generating new tables, now integrated with the Monte Carlo simulations. This model was validated by the Financial Planning team of the projects.

Later, during the execution of the projects, the conventional indicators of EVM were generated and the new ones that included the simulation were generated. These tables were then analyzed in meetings involving the six area coordinators according to Figure 2 who were: a global engineering manager, two planning managers, a project director, and two operation directors who effectively represented the company's corporate board.

Subsequently, unstructured interviews were carried out with the Financial Planning team in order to capture the results of the analysis by the managers and verify the impact of the model use. Figure 3 summarizes the steps for collecting the information.

Tables 1 and 2 show, as an example for project $\mathrm{C}$, the main traditional data (step 2 of Figure 3 ) obtained from EVM for the third month of this project:

Similar tables were obtained for all months of projects A and B, whose budgets are in Table 3 .

\subsection{Model to simulation}

For the cost projections, the model proposed by Vargas (2004) suggests the adoption of three indexes, which compose the triangular probability distributions determined for each work package (in this case, the six areas) whose costs are added to the total project.

The optimistic view considers that the best CPI can be equal to 1, according to Doskočil (2015), that is, the rest of the work will be done as planned. Therefore, the estimate of the term would be given by the sum of the costs already incurred with the work to be done considering such CPI, according to Equation 6.

$$
E A C=A C W P+(B A C-B C W P) / 1
$$

The probable view considers the historical CPI seen in the project in each activity, i.e., it predicts that the final costs will follow the same trend, according to Equation 7.

$$
E A C=A C W P+(B A C-B C W P) / C P I
$$

The pessimistic view considers a combined CPI trend with RLS, the effort to make up for lost time.

\begin{tabular}{|c|l|}
\hline Step $1 \rightarrow$ & No structured interview to obtain the goals of the research for the firm \\
Step $2 \rightarrow$ & Obtain access to data of the project's costs and the traditional EVM index \\
\hline Step $3 \rightarrow$ & Development of a new set group model to integrate of the EVM simulation \\
Step $4 \rightarrow$ & Model validation with the financial planning of the project \\
\hline Step $5 \rightarrow$ & During the project index traditional criation and the new index \\
Step $6 \rightarrow$ & Show the data at firm meeting and the project attendance \\
Step $7 \rightarrow$ & No structured interview with the planning to report the sugestions \\
\hline
\end{tabular}

Figure 3. Stages of research.

Table 1. EVM data to the third month of Project C.

\begin{tabular}{lcrrrr}
\hline \multicolumn{1}{c}{ Area } & \% Complete & \multicolumn{1}{c}{ BAC } & BCWS & BCWP & ACWP \\
\hline Total Eng & $\mathbf{3 7 . 3 1}$ & $\mathbf{1 , 5 4 9 , 0 8 9}$ & $\mathbf{1 , 3 5 5 , 2 6 2}$ & $\mathbf{5 7 8 , 0 0 4}$ & $\mathbf{5 2 0 , 8 2 6}$ \\
Process & 78.87 & 107,010 & 89,966 & 84,399 & 83,258 \\
Civil & 29.54 & 412,729 & 412,729 & 121,923 & 121,077 \\
Piping & 24.06 & 449,143 & 417,703 & 108,047 & 110,910 \\
Mechanics & 36.72 & 201,518 & 161,487 & 74,004 & 86,173 \\
Instrum. & 44.66 & 218,328 & 143,914 & 97,500 & 54,723 \\
Electrical & 43.69 & 160,362 & 129,462 & 70,057 & 64,685 \\
\hline
\end{tabular}

Table 2. EVM indicators to the third month of Project C.

\begin{tabular}{lcccccccc}
\hline \multicolumn{1}{c}{ Area } & \% Complete & CV & SV & CPI & SPI & EAC SCI & $\begin{array}{c}\text { EAC } \\
\text { Constant }\end{array}$ & EAC CPI \\
\hline Total Eng & $\mathbf{3 7 . 3 1 \%}$ & $\mathbf{5 7 , 1 7 9}$ & $\mathbf{- 7 7 7 , 2 5 8}$ & $\mathbf{1 . 1 1 0}$ & $\mathbf{0 . 4 2 6}$ & & & \\
Process & $78.87 \%$ & 1,141 & $-5,567$ & 1.014 & 0.938 & 100,651 & 105,563 & 115,559 \\
Civil & $29.54 \%$ & 846 & $-290,806$ & 1.007 & 0.295 & 344,774 & 409,866 & 536,514 \\
Piping & $24.06 \%$ & $-2,863$ & $-309,656$ & 0.974 & 0.259 & 373,291 & 461,042 & 598,189 \\
Mechanics & $36.72 \%$ & $-12,169$ & $-87,484$ & 0.859 & 0.458 & 184,260 & 234,654 & 268,335 \\
Instrum. & $44.66 \%$ & 42,776 & $-46,415$ & 1.782 & 0.677 & 147,668 & 122,540 & 227,336 \\
Electrical & $43.69 \%$ & 5,372 & $-59,405$ & 1.083 & 0.541 & 134,150 & 148,065 & 193,692 \\
\hline
\end{tabular}


In case of delayed projects, generally the two indexes will be less than 1, resulting in a higher EAC, seen in Equation 8.

$$
E A C=A C W P+(B A C-B C W P) /(C P I x S P I)
$$

It was found that CPI and SPI are not always less than 1, where the applied model used triangular distributions, with slightly different equations to determine these probability distribution functions. In this company, a CPI of 0.7 is considered practically unacceptable, since a value below this can show more than low productivity, possibly indicating measurement failures or deviations in the planning or usage and for the pessimistic view, the Equation 9.

Table 3. Budget of projects A and B.

\begin{tabular}{ccc}
\hline Discipline & BAC - Proj A & BAC - Proj B \\
\hline Total Eng & $\mathbf{2 , 2 6 3 , 2 5 4}$ & $\mathbf{7 3 0 , 9 9 9}$ \\
Process & 92,425 & 37,800 \\
Civil & 756,970 & 194,730 \\
Piping & 628,969 & 263,412 \\
Mechanics & 339,029 & 75,205 \\
Instrum. & 210,428 & 55,523 \\
Electrical & 235,432 & 104,330 \\
\hline
\end{tabular}

$$
E A C=A C W P+(B A C-B C W P) / 0.7
$$

The most likely view is that the CPI will be repeated until the end of the project, according to Equation 7. The optimistic view, however, will consider that the projected work can be done with resource savings, higher than the one fixed at the baseline, ie with a CPI greater than 1 (Doskočil, 2015). Thus, the CPI used will be 1.3, according to Equation 10, and may also show measurement failures or deviations in the planning.

$$
E A C=A C W P+(B A C-B C W P) 1,3
$$

With these equations, Tables 4, 5 and 6 were prepared for calculations referring to the seventh month of project $A$.

The final costs of the project (EAC) were therefore simulated as a sum in function of the triangular distributions of probabilities of the six specialties of the project, specified according to the presented equations.

\section{Result analysis}

For each month and for each of the three projects, the three tables were generated according to

Table 4. EVM data for the seventh month of project A.

\begin{tabular}{ccrrrr}
\hline Area & \% Complete & \multicolumn{1}{c}{ BAC } & BCWS & BCWP & ACWP \\
\hline Total Eng & $\mathbf{9 5 . 8 4 \%}$ & $\mathbf{2 , 0 9 3 , 5 2 0}$ & $\mathbf{1 , 9 9 6 , 1 2 2}$ & $\mathbf{2 , 0 0 6 , 3 3 7}$ & $\mathbf{2 , 0 2 2 , 8 2 6}$ \\
Process & $99.12 \%$ & 88,562 & 82,894 & 87,785 & 80,751 \\
Civil & $89.63 \%$ & 724,566 & 746,346 & 649,415 & 817,702 \\
Piping & $91.44 \%$ & 588,184 & 499,249 & 537,844 & 545,376 \\
Mechanics & $74.95 \%$ & 297,153 & 284,455 & 222,727 & 243,390 \\
Instrum. & $92.03 \%$ & 193,027 & 185,072 & 177,635 & 142,953 \\
Electrical & $82.89 \%$ & 202,027 & 198,106 & 167,467 & 192,653 \\
\hline
\end{tabular}

Table 5. EVM indicators to the seventh month of Project A.

\begin{tabular}{crrrc}
\hline Area & CV & SV & CPI & SPI \\
\hline Total Eng & $\mathbf{- 1 6 , 4 8 9}$ & $\mathbf{1 0 , 2 1 5}$ & $\mathbf{0 . 9 9 2}$ & 1.087 \\
Process & 7,034 & 4,892 & 0.794 & 1.059 \\
Civil & $-168,286$ & $-96,931$ & 0.986 & 0.870 \\
Piping & $-7,531$ & 38,596 & 0.915 & 1.077 \\
Mechanics & $-20,664$ & $-61,729$ & 1.243 & 0.783 \\
Instrum, & 34,682 & $-7,437$ & 0.869 & 0.960 \\
Electrical & $-25,187$ & $-30,639$ & & 0.845 \\
\hline
\end{tabular}

Table 6. Parameters of the triangular distributions of each area of project A in the seventh month.

\begin{tabular}{ccccl}
\hline Area & \multirow{2}{*}{ EAC Optim. } & \multirow{2}{*}{ EAC Prov. } & \multirow{2}{*}{ EAC Pessim. } & \\
\cline { 1 - 2 } Total Eng & & & & Distributions \\
\cline { 1 - 1 } Process & 81,348 & 81,465 & 81,860 & $=$ triang (Optim EAC; Prob.EAC; Pessim.EAC) \\
Civil & 875,510 & 912,327 & 925,060 & $=$ triang (Optim EAC; Prob.EAC; Pessim.EAC) \\
Piping & 584,099 & 596,421 & 617,290 & $=$ triang (Optim EAC; Prob.EAC; Pessim.EAC) \\
Mechanics & 300,641 & 324,722 & 349,713 & $=$ triang (Optim EAC; Prob.EAC; Pessim.EAC) \\
Instrum. & 154,793 & 155,340 & 164,942 & $=$ triang (Optim EAC; Prob.EAC; Pessim.EAC) \\
Electrical & 219,238 & 232,412 & 242,026 & $=$ triang (Optim EAC; Prob.EAC; Pessim.EAC) \\
\hline
\end{tabular}


Tables 4, 5 and 6, which show, as an example, the deterministic indicators defined by EVM measured in the seventh month of project A. Through these indicators and the attribution of probability distributions of the CPIs of each area, it was possible to generate the monthly budget simulations. Figure 4 shows the triangular distribution connected to the Process area in the seventh month of project A:

We notice that the values of greater probability, are to the left, so it shows a greater trend of compliance

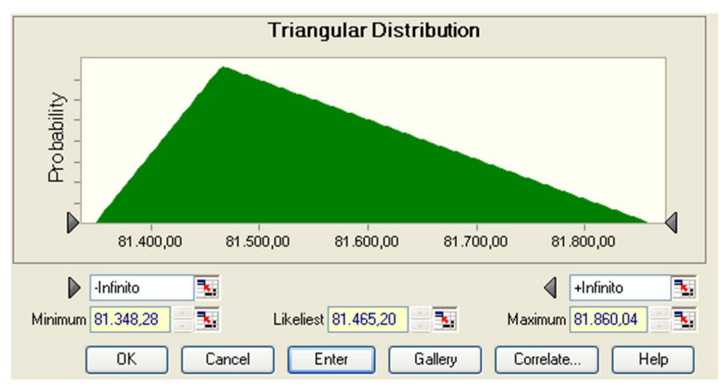

Figure 4. Triangular distribution of process area costs.

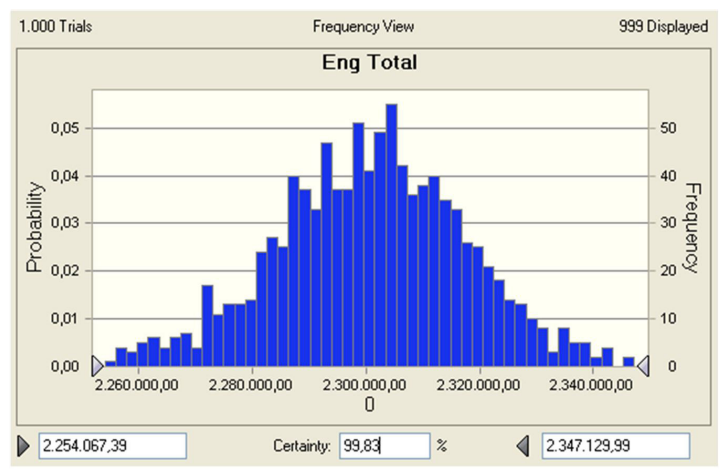

Figure 5. Distribution of final project costs. of the budget by the area of Processes, with CPI closer to 1.3 than to 0.7 .

Once this was done for all areas of the three projects, it was possible to simulate the final cost of the project (Total Engineering) by stipulating a number of 1000 rounds, with a stop when the confidence level reaches $95 \%$.

By combining EVM with Monte Carlo simulation, the result of this simulation is a curve. For the seventh month of project $A$, the result of Figure 5 was obtained as follows:

Figure 5 shows that, for a range of $99.83 \%$ accuracy, the final project costs will be between $\mathrm{R} \$ 2,254,067.39$ and $\mathrm{R} \$ 2,347,129.99$, that is, between $107.7 \%$ and $112.1 \%$ of the initial BAC. These simulations were executed for all months of the three projects, generating a summary (Tables 7, 8 and 9).

For the simulations, months 1 and 2 of each project were excluded because, in those months, the initial costs of the detailing project were recognized in the previous phase, of basic design. This led to large distortions in CPI, and conclusions cannot be drawn from this indicator. In addition, it was during these months that the integrated model of EVM with Monte Carlo was developed for each project. But even with the exclusion of the initial two months of the period of analysis, CPIs remained high in the following months, since they are cumulative indicators. Thus, it was necessary to change the Equations 9 and 10 that started to have the factors of 1.3 and 0.7 by multiplying CPI depending on which value the index exceeded. This significantly altered the probability distributions, but the results of the simulations did not oscillate abnormally.

Regarding the costs considered, the Financial Planning team decided to include only those related to direct labor. Costs of travel, telephone, energy,

Table 7. Monthly simulations of the final costs of project A.

\begin{tabular}{|c|c|c|c|c|c|c|c|c|}
\hline Project A & Month 3 & Month 4 & Month 5 & Month 6 & Month 7 & Month 8 & Month 9 & Month 10 \\
\hline $\begin{array}{l}\text { Final } \\
\text { Cost-beginning } \\
\text { of the interval }\end{array}$ & $1,752,014$ & $1,812,244$ & $2,001,889$ & $2,136,171$ & $2,278,409$ & $2,317,599$ & $2,426,553$ & $2,665,237$ \\
\hline $\begin{array}{l}\text { Final Cost - end } \\
\text { of the interval }\end{array}$ & $2,170,719$ & $2,109,863$ & $2,197,353$ & $2,251,492$ & $2,350,679$ & $2,364,979$ & $2,453,433$ & $2,682,392$ \\
\hline $\begin{array}{l}\text { Confidence } \\
\text { Interval }\end{array}$ & $95 \%$ & $95 \%$ & $95 \%$ & $95 \%$ & $95 \%$ & $95 \%$ & $95 \%$ & $95 \%$ \\
\hline $\begin{array}{l}\text { Probab. or lower } \\
\text { BAC }\end{array}$ & $99.9 \%$ & $100.0 \%$ & $100.0 \%$ & $99.0 \%$ & $0.2 \%$ & $0.0 \%$ & $0.0 \%$ & $0.0 \%$ \\
\hline
\end{tabular}

Table 8. Monthly simulations of the final costs of project B.

\begin{tabular}{lcccccc}
\hline \multicolumn{1}{c}{ Project B } & Month 3 & Month 4 & Month 5 & Month 6 & Month 7 & Month 8 \\
\hline Final Cost - beginning of the & 567,397 & 597,140 & 591,507 & 609,072 & 714,484 & 826,796 \\
interval & & & & & & \\
Final Cost - end of the interval & 860,833 & 893,320 & 745,286 & 664,956 & 741,796 & 838,237 \\
Confidence Interval & $95 \%$ & $95 \%$ & $95 \%$ & $95 \%$ & $95 \%$ & $95 \%$ \\
Probab, or lower BAC & $65.5 \%$ & $43.6 \%$ & $94.4 \%$ & $100.0 \%$ & $67.1 \%$ & $0.0 \%$ \\
\hline
\end{tabular}


Table 9. Monthly simulations of final costs of project C.

\begin{tabular}{ccccc}
\hline Project C & Month 3 & Month 4 & Month 5 & Month 6 \\
\hline Final Cost - beginning of the interval & $1,421,033$ & $1,503,430$ & $1,724,840$ & $1,679,912$ \\
Final Cost - end of the interval & $1,696,793$ & $1,696,858$ & $1,882,508$ & $1,741,750$ \\
Confidence Interval & $95 \%$ & $95 \%$ & $95 \%$ & $95 \%$ \\
Probab. or lower BAC & $46.4 \%$ & $14.3 \%$ & $0.0 \%$ & $0.0 \%$ \\
\hline
\end{tabular}

Table 10. Physical progress and evolution of CPI in project A (reweighting in month 8).

\begin{tabular}{cccccccccc}
\hline Total Eng. & Month 3 & Month 4 & Month 5 & Month 6 & Month 7 & Month 8 & Month 9 & Month 10 & Month 11 \\
\hline \% Complete & $45.6 \%$ & $59.0 \%$ & $69.5 \%$ & $85.9 \%$ & $95.8 \%$ & $93.3 \%$ & $95.9 \%$ & $98.0 \%$ & $100.0 \%$ \\
CPI & 1.384 & 1.300 & 1.154 & 1.142 & 1.072 & 0.973 & 0.930 & 0.847 & 0.820 \\
\hline
\end{tabular}

space, among other indirect costs, were not included because they did not generate physical progress and were not totally under the control of the supervisors of the six measured areas. Its inclusion could reduce the variation of the indicators evaluated, inflating the total costs, thus reducing the percentage deviation of its components and covering a possible budget problem in the heading of direct labor.

From Tables 7 to 9, there are problems with the budget in the sixth month in case of project A, with the probability of obtaining a lower cost than the one defined for the project. In that month, costs (ACWP) accounted for $61.7 \%$ of total costs actually incurred (final ACWP, Table 8) and accounted for $75.2 \%$ of the budget (BAC, Table 3). In the seventh month, it was confirmed that the total costs would be higher than expected with the probability of $0.23 \%$ compliance with the BAC.

Analyzing Table 10, the project already had more than $95 \%$ of physical progress in the seventh month, leaving 3 months of activities and only $10.6 \%$ of the budget. Thus, it would be possible to change the plan with corrective actions, minimizing the excess of the anticipated costs. Despite the short notice, the model made it possible to anticipate problems with budget.

In a comparison with the traditional deterministic method, using the historical CPI $(1,072)$ for a projection, the final value of the costs would be $\mathrm{R} \$ 2,302,686.10$, already representing a small increase, but without demonstrating the magnitude of the problem. The probability of the historical CPI value is lower than $30 \%$, thus representing a risk of at least $70 \%$ of mistake when assuming such value (Figure 6).

The same analyses were carried out in relation to project $\mathrm{B}$. The projection of final costs fluctuated within the BAC among months 3 and 6 , evidencing some control of the budget. In the seventh month, there was recognition of Pipeline scope changes. With the client acknowledging that part of the project carried out were not initially budgeted, there was an increase in the budget available for the area. However, much of the costs had already been incurred in the previous months. Thus, even with this recognition, the model

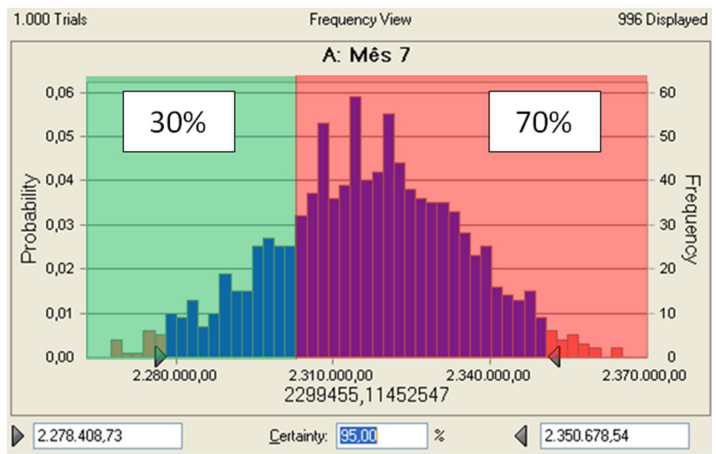

Figure 6. Probability of EAC occurrence based on historical $\mathrm{CPI}$ and its risk.

pointed out that costs would exceed the BAC, even with two remaining months of project. This warning occurred before project $\mathrm{A}$, since progress at that time was $88.59 \%$ and $87.3 \%$ of project execution. In indicating such a situation with a less progress, besides evidencing the necessity of the elaboration of an action plan, it was possible to realize that project $\mathrm{B}$ had a worse performance when compared to the project $\mathrm{A}$.

Part of the justification for Project B performance is that not all scope changes were raised and included in the BAC, with only "Piping" quantifying the costs of activities not included in the initial scope. Therefore, it cannot be said whether the project, for the same budgeted scope, exceeded the BAC. For the considered scope in the seventh month, there was this signaling.

In the comparison with the deterministic method, projecting the final costs by the historical CPI of that month, the risks are practically the same as in project A. By the traditional projection through CPI, the costs would be R $\$ 724,808.42$, that is, $99.1 \%$ of BAC, thus not overspending. By the simulation, the probability of occurrence of costs less than or equal to the historical CPI projection is approximately $35 \%$, representing a risk of $65 \%$ if such value is assumed. 
Analyzing Project $\mathrm{C}$, the third month the probability of meeting BAC was small. In the fourth month, with less than $15 \%$ probability of meeting the budget, it had $56.7 \%$ of physical progress and an incurred cost of $54.2 \%$ of BAC or, still, $49.6 \%$ of the final costs of the project. In this case, it is evident the great contribution of the tool, able to anticipate the budget problems even in the project that had the lowest overestimate of expected costs (Table 11).

So for project C, the use of the historical CPI of the fourth month would produce a projected cost of $\mathrm{R} \$ 1,587,888.33$, that is, an increase of only $2.5 \%$. Equal or lower would have a probability of occurrence of approximately $40 \%$, symbolizing a $60 \%$ risk of higher values, as it happened.

For the three projects it was also possible to analyze the evolution of the forecast intervals, as illustrated for project B (Figure 7).

Figure 7 shows the narrowing of the forecast intervals. In addition, we can observe the reversion of the trend that, during the first three months of analysis, the project was within the budget, while in the latter the opposite was signaled. This reversal is a good indicator of the triggering of correction plans.

You can view the impact of the scope changes on EVM tracking charts by analyzing Project A. Figure 8 below shows the final graph of project A.

In Figure 8, the costs incurred slightly outweigh the altered baseline. If the analysis were to continue without the incorporation of the scope changes, this deviation would be greater, besides the management error, because the same effort would be required to carry out a larger scope. This would be in contradiction with one of the basic principles for the application of EVM, which is the definition of scope. Therefore, it is possible to infer analyzes on the projects scope, proving the value of EVM technique (Figure 8).

By changing the baseline, creating a new one for comparison, new CPI declines in relation to this new line should be explained again in order to identify the causes. With a chart with the original, unalterable scope, it would not be possible to identify to what extent a low CPI is due to unproductiveness, rework or the basis of comparison of different scopes.

So far, the mentioned analyses are of a more quantitative nature, being carried out by the Financial Planning team and collected before the project follow-up meetings. At these meetings, however, besides analyzing a graph of total performance of all engineering, the performance of each of the six areas was analyzed, noting not only the evolution of the CPI, but the reasons for this evolution and how it could solve problems. Therefore, the following assessments were recorded after these meetings, through unstructured interviews.

Analyzing the evolution of CPI, one area that stood out was Piping, which performed among the worst in all projects (Table 12).

In Project A, where Piping had the lowest percentage overrun, the area contributed alone with almost $50 \%$ of the entire project budget deviation due to constant project adjustments. Many of the assumptions adopted, i.e information that other areas or suppliers should deliver in order to proceed with the detailing of the pipe lines, were not sent on time or were not confirmed, which reflected a greater design effort

Table 11. Confrontation between the budget and the actual final costs of the three projects.

\begin{tabular}{crrc}
\hline Project & Budget(BAC) & $\begin{array}{c}\text { Actual } \\
\text { final cost } \\
\text { (ACWP final) }\end{array}$ & $\begin{array}{c}\text { Exceeding } \\
\text { expected } \\
\text { costs \% }\end{array}$ \\
\hline A & $2,263,254$ & $2,759,927$ & 21.9 \\
B & 730,999 & 885,165 & 21.1 \\
C & $1,549,089$ & $1,694,062$ & 9.4 \\
\hline
\end{tabular}

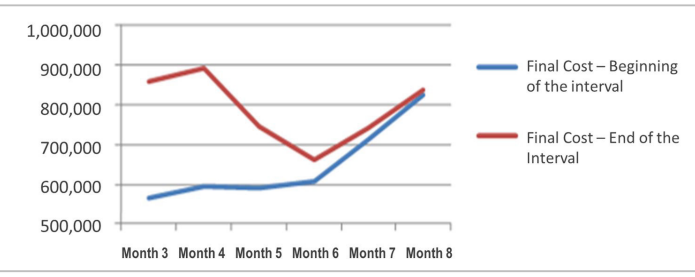

Figure 7. Evolution of the forecast intervals for project B.

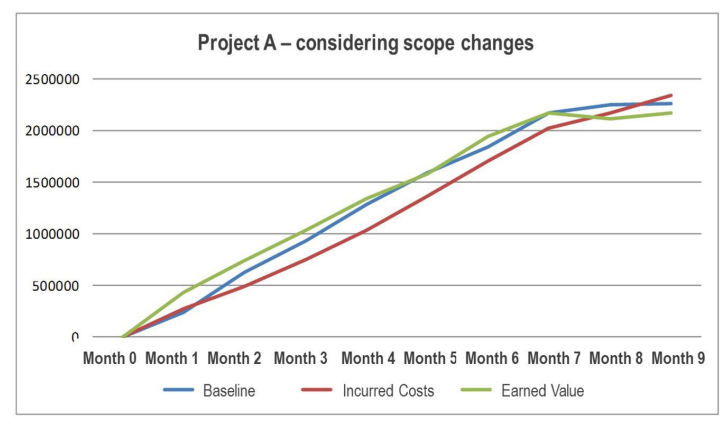

Figure 8. EVM chart for project A, with changes in scope.

Table 12. CPI Evolution of piping in the three projects.

\begin{tabular}{cccccccccc}
\hline Project & Month 3 & Month 4 & Month 5 & Month 6 & Month 7 & Month 8 & Month 9 & Month 10 & Month 11 \\
\hline A & 1.039 & 1.062 & 1.063 & 1.128 & 1.055 & 0.950 & 0.848 & 0.774 & 0.722 \\
B & 0.766 & 0.640 & 0.764 & 0.860 & 0.811 & 0.714 & 0.672 & - & - \\
C & 0.974 & 0.926 & 0.854 & 0.810 & 0.831 & - & - & - & - \\
\hline
\end{tabular}


(and thus hours of engineers) to anticipate some of the situations. This major effort was not fully recognized as a baseline change and the performance of the area was penalized.

In relation to the Processes area, it is noted that CPI was a disproportion in Project $C$. This was explained because it is a project of a not so traditional sector for the engineering company so, the amount of resources budgeted in the baseline turned out to be very bold. In project $A$, the area showed a worsening in the last months of the projects due to pending projects that consumed more resources than expected and did not allow the project to be completed. In addition, engineering teams warned that some project $B$ costs were released in project $\mathrm{A}$, which explains the opposite trend in CPI evolution. Table 13 shows the evolution of the Process indicator.

The Mechanical area is another that deviates from the most preliminary stages of the project, such as Processes. For this reason, Project $\mathrm{C}$ started out below the others, for the same reason as the new scope. Despite this, there has been an apparent recovery in recent months with the recognition of the progress of some expenses that had already been incurred. Expenses for the final issuance of these documents were incorporated in months 4 and 5, while physical progress was present only in the last two months. Thus, despite the compensations, in projects $\mathrm{A}$ and $\mathrm{B}$, CPI ended near 1 , evidencing the good performance of the area. Table 14 shows the evolution of CPI of Mechanics.

Regarding the compensation between projects, in this area it was possible to reallocate some of the costs when the launching in a given project was considered undue. However, because it was practically the same team working on all three projects in the six areas and almost simultaneously, it was inevitable that some values would be allocated inaccurately, as observed by Martins (2010). Part of this imprecision stems from the distribution of indirect labor, since sometimes shared supervision costs are eventually distributed among the projects by apportionment. The launching of direct costs can also have the same imprecision, since the appointment of hours is done by each professional, through an electronic system, not keeping a mandatory database with the projects worked, and there may be inaccuracies in the postings of each professional.

The Instrumentation area presented good performance. Only in the last month of project B was with a CPI less than 1 due to the imprecision in the division between the detailing project and the next stage of the project, that is, part of the costs recognized at the end of project $B$ are not part of the detailing, but part of the attendance of the professional request in work and cannot be counted in the assistance stage. In this case, since there is a demand from the Instrumentation professionals, the proposal elaboration team or the team responsible for the revision of the project budget, should re-evaluate the negotiated values and the budget for Instrumentation in case of new projects with similar scopes. Table 15 shows the CPI Evolution of Instrumentation in three projects.

Electrics finished all three projects with a CPI slightly above 1 (and below 1.3), signaling that projects were conducted as planned and at or above the baseline in terms of budget. In terms of monthly physical progress, with the large swing of the CPI which, in project $\mathrm{B}$, reached 1.375 to finish at 1.101 , the baseline curve could be reweighted. Table 16 shows the evolution of the indicator.

The Civil area deserved special attention. In projects $\mathrm{A}$ and $\mathrm{B}, \mathrm{CPI}$ started with very high values (above 1.3), showing great physical advances with the consumption of few resources, whereas the situation reversed at the end. During the project, recoveries

Table 13. CPI Evolution of Processes in the three projects.

\begin{tabular}{cccccccccc}
\hline Project & Month 3 & Month 4 & Month 5 & Month 6 & Month 7 & Month 8 & Month 9 & Month 10 & Month 11 \\
\hline A & 2.000 & 1.570 & 1.398 & 1.251 & 1.135 & 1.121 & 1.047 & 0.910 & 0.834 \\
B & 0.796 & 0.903 & 0.989 & 1.033 & 1.054 & 1.058 & 1.036 & - & - \\
C & 1.014 & 0.836 & 0.474 & 0.446 & 0.445 & - & - & - & - \\
\hline
\end{tabular}

Table 14. CPI Evolution of Mechanics in the three projects.

\begin{tabular}{clllllllll}
\hline Project & Month 3 & Month 4 & Month 5 & Month 6 & Month 7 & Month 8 & Month 9 & Month 10 & Month 11 \\
\hline A & 1.102 & 1.146 & 1.023 & 0.995 & 1.044 & 1.077 & 1.050 & 0.966 & 1.028 \\
B & 0.837 & 0.797 & 0.905 & 1.013 & 1.009 & 0.967 & 0.981 & - & - \\
C & 0.859 & 0.707 & 0.689 & 0.822 & 0.990 & - & - & - & - \\
\hline
\end{tabular}

Table 15. CPI Evolution of Instrumentation in three projects.

\begin{tabular}{cccccccccc}
\hline Project & Month 3 & Month 4 & Month 5 & Month 6 & Month 7 & Month 8 & Month 9 & Month 10 & Month 11 \\
\hline A & 1.715 & 1.619 & 1.429 & 1.247 & 1.355 & 1.426 & 1.385 & 1.208 & 1.199 \\
B & 1.366 & 1.356 & 1.567 & 1.350 & 1.195 & 1.005 & 0.868 & - & - \\
C & 1.782 & 1.670 & 1.526 & 1.591 & 1.395 & - & - & - & - \\
\hline
\end{tabular}


Table 16. CPI Evolution of electric in the three projects.

\begin{tabular}{cccccccccc}
\hline Project & Month 3 & Month 4 & Month 5 & Month 6 & Month 7 & Month 8 & Month 9 & Month 10 & Month 11 \\
\hline A & 1.362 & 1.309 & 1.170 & 1.203 & 1.013 & 1.050 & 0.983 & 1.056 & 1.056 \\
B & 1.143 & 1.315 & 1.375 & 1.304 & 1.073 & 1.101 & 1.101 & - & - \\
C & 1.083 & 1.133 & 1.025 & 1.104 & 1.104 & - & - & - & - \\
\hline
\end{tabular}

Table 17. CPI Evolution of Civil in the three projects.

\begin{tabular}{cccccccccc}
\hline Project & Month 3 & Month 4 & Month 5 & Month 6 & Month 7 & Month 8 & Month 9 & Month 10 & Month 11 \\
\hline A & 1.559 & 1.386 & 1.137 & 0.932 & 0.830 & 0.838 & 0.847 & 0.747 & 0.721 \\
B & 30.203 & 15.132 & 4.522 & 2.331 & 1.335 & 0.955 & 0.880 & - & - \\
C & 1.007 & 0.988 & 0.890 & 1.018 & 1.012 & - & - & - & - \\
\hline
\end{tabular}

of the physical progress curve and the percentage representativeness of civil advances in the advance of Total Engineering were performed in order to represent the great weight of this area in the budget.

This area was also largely responsible for the budget overruns in the projects, and is difficult to be manage, given the wide scope. In addition, it has part of the scope being subcontracted, which provides higher costs and a greater distance in terms of management. Even with these difficulties, in project $\mathrm{C}$, the area faced fewer problems even considering the experiences of projects $\mathrm{A}$ and $\mathrm{B}$, which were already in progress.

The Civil indicators are shown in Table 17.

According to the interviews, the interviewees were told that the monthly contact between the project manager and the coordinators of the six engineering areas was intense so that these indicators could be improved, despite the justifications raised for the performance of the areas. Reductions were requested in the consumption of hours for the project execution or, if it were not possible, the allocation of people with lower wages, as measures to reduce the cost of the project. However, this is not always possible, since it is necessary to consider the term, as EVM shows in the accompanying curves, and the quality.

At the end of the project, one can evaluate the consideration of Lipke et al. (2009), comparing the evolution of the overall CPI of the project against its final value, which is nothing more than an average value of CPI. If this final CPI were followed monthly or if it were only obtained in the last month of the project, as a result of the accumulated monthly variations, the overall result obtained would be the same. However, for forecasting purposes, this variation is important. If the monthly CPIs are used to estimate the final costs, the greater the oscillation of these CPIs, the greater the difference between the forecasts made. With the simulation use, this was mitigated with the triangular probability distribution that governs the generation of random CPIs used in the generated multiple predictions (Grey, 1995; Vose, 2008; Kim, 2016). Figures 9 to 11 show the variations of total CPI in the three designs.

It is noted that the CPI variations were large. At the beginning of the project, the figures were well

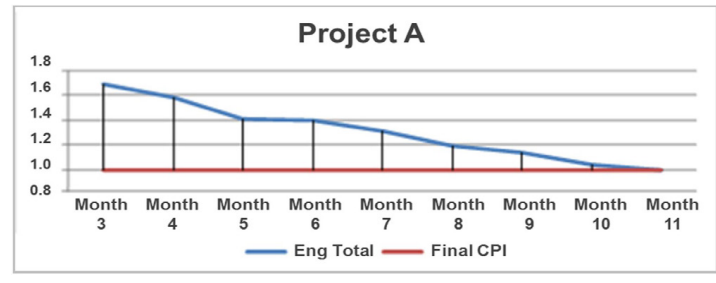

Figure 9. Variation of monthly CPIs vs. final in project A (in\%).

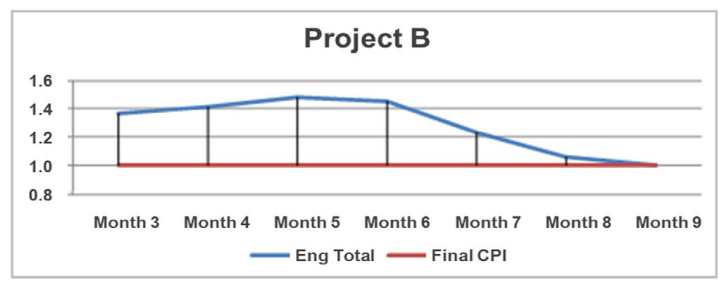

Figure 10. Variation of monthly CPIs vs. final in project B (in \%).

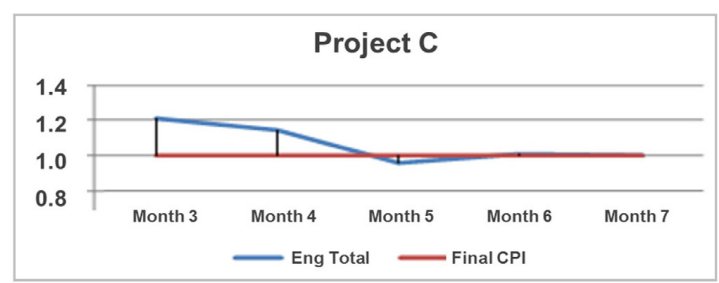

Figure 11. Variation of monthly CPIs vs. final in project C (in\%).

above the final ones, which could lead to the wrong idea that the projects would end up within the budget. Only in project $C$ the variation was $20 \%$ from the middle of the project (month 3 ) to its end (month 7). In projects $\mathrm{A}$ and $\mathrm{B}$, the variation, on the same basis of comparison, was more than $40 \%$. Therefore, the statement of Payne (1990), Lipke (2003), Henderson \& Zwikael (2008), Lipke et al. (2009) and Koning \& Vanhoucke (2016) that small projects do not show CPI stabilization has been verified.

This variation of CPI observed in projects $A$ and B may be linked to Zwikael's statement et al. (2000) where the CPI stabilization depends on a large extent on the accuracy of the original budget and the ability of the project manager to correct deviations, keeping within the initial schedule. According to Zwikael et al. (2000), these factors vary according to the 
particularities of each company. There is also the question of the size and length of the project, which is related to the non-stabilization of the CPI, which, according to Lipke (2003), is related to the number of observations collected in a short intervalsuggesting a greater accuracy and precision in the data collection, requiring a greater monitoring by the managers. This statement is also seen in Custer (2008), which suggests that there is a greater monitoring in the execution phases of small projects because of their length.

For Lipke (2011), the late CPI stabilization may also be related to two factors that are Down Time - periods within the schedule where no work is scheduled, and Stop Work - periods during project execution, where interrupts project follow-up. This, according to Lipke (2011), does not influence CPI in large projects with long periods. However, in small and short length projects, these factors have a greater impact on CPI behavior, as observed in projects A and B. Another factor raised by Koning \& Vanhoucke (2016) related to non-stabilization of CPI is the size of the management team, associated to the efficiency in obtaining the data for CPI calculation with greater efficiency where, in small projects and of short length, this process may not occur; but there is no support within the literature to corroborate this statement.

The adoption of the initial CPI values would, in fact, only generate the lowest expected values, entailing great risks to the project costs management. Thus, Monte Carlo simulation proved to be useful from a managerial point of view when combined with EVM.

Therefore, with the model used it helps to know if the project would run as expected or not. Therefore, it was possible to observe the occurrence of an amount equal to or less than that expected in the budget. When this chance decreases or reverses the trend, regardless of the CPI, an action plan can already be drawn, identifying where the apparent worsening has occurred. So, the integration of the tools was able to produce a better result than some scenarios simulated from a CPI obtained in a given month.

In this particular case, the importance of aligning Cost Breakdown Structure (CBS) and Work Breakdown Structure (WBS) at the beginning of the project with good scope management was proven, as this would have prevented budget changes and high CPIs from interfering with the simulations. In the present work, it was verified that Financial Planning adopted some strategies (such as separation of costs and progress of the detailing phase from those destined to the other phases of the project, disregarding the first months of the detailing and the incorporation of the costs of the scope changes in the budget) that did not compromise the model, which was able to show the achieving that occurred in the analyzed projects.

\section{Conclusions}

Project management is the competitive advantage for monitoring and managing non-routine activities, such as product development. One of the techniques that has also gained acceptance is EVM, which enables the integrated control of the scope, costs and deadlines of projects and their stages. EVM with Monte Carlo simulation allows for a refined cost forecasting by making it probabilistic.

The objective of this work was to analyze the impacts brought by the application of EVM associated with the Monte Carlo simulation in the forecast of the final costs of three detailed engineering projects, analyzing the management impacts of the model use, combining its gains and limitations. It was noted that the application of the techniques stimulated the follow-up meetings, making it possible to evaluate the indicators in the pure EVM, besides the probabilities of overspending the budget obtained in the simulations.

The CPI variations served to prove that there was no stabilization of the cost indicator. This fact, as observed in two of the three projects analyzed (A and B) is supported by the specialized literature, seen in Payne (1990), Christensen \& Payne (1992), Zwikael et al. (2000), Henderson \& Zwikael (2008), Lipke et al. (2009), Lipke (2011), Koning \& Vanhoucke (2016).

On the limitations of its application, it did not occur from the beginning and some problems arose from the non-alignment between CBS and WBS initially. With the strategies developed it was possible to manage the project through EVM. Also, the importance of good management and the quantification of the scope changes has been proven to maintain a valid parameter for comparison.

For future work, it is suggested the application of the model in other sectors and / or other projects, comparing the results, verifying similarities and/or divergences in the integration of EVM with Monte Carlo. In the field in addition to the detailing phase, it is recommended to include the direct and indirect costs of the construction activity, to verify if the integration with the simulation solves some limitations of the pure EVM.

\section{Acknowledgements}

The authors would like to thank Karl E. Schneider of the Michigan State University for the textual review and any errors and omissions are the responsibility of the authors.

\section{References}

Acebes, F., Pajares, J., Galán, J. M., \& López-Paredes, A. (2014). A new approach for project control under uncertainty. Going back to the basics. International Journal of Project Management, 32(3), 423-434. http:// dx.doi.org/10.1016/j.ijproman.2013.08.003. 
Acebes, F., Pereda, M., Poza, D., Pajares, J., \& Galán, J. M. (2015). Stochastic earned value analysis using Monte Carlo simulation and statistical techiniques. International Journal of Project Management, 33(7), 1597-1609. http:// dx.doi.org/10.1016/j.ijproman.2015.06.012.

Associação Brasileira de Normas Técnicas - ABNT. (2012). NBR ISO 21500:2012 - orientações sobre gerenciamento de projeto. Rio de Janeiro: ABNT.

Baena, W. C. (2010, fevereiro). Qual o preço de venda de um projeto? E-News PMI. São Paulo.

Barbosa, L. C., \& Lopes, I. C. (2016). Empresas versus Processos seletivos: a importância do recrutamento e da seleção para o desenvolvimento organizacional. Revista de Administração e Comércio Exterior, 2(1), 2-16.

Batselier, J., \& Vanhoucke, M. (2015). Evaluation of deterministic state-of-the-art forecasting approaches for projects duration based on Earned Value Management. International Journal of Project Management, 33(7), 15881596. http://dx.doi.org/10.1016/j.ijproman.2015.04.003.

Berssaneti, F. T., Assumpção, A., \& Nakao, O. S. (2014). Engenharia e construção: quais variáveis contribuem para o sucesso dos projetos executados atualmente no Brasil. Gestão \& Produção, 21(1), 95-109. http://dx.doi. org/10.1590/S0104-530X2014005000009.

Brandão, R. P. P., Silva, P. B. I., \& Silva, L. S. (2016). Método de Monte Carlo: um estudo de caso aplicado ao Gerenciamento de Projetos. In Anais do $8^{\circ}$ Encontro Científico de Administração, Economia e Contabilidade - ECAECO (pp. 1-14). Dourados: UEMS.

Breitman, K. K. (2012). Arcabouço para desenvolvimento se serviços baseados na Simulação de Monte Carlo na Cloud. (Tese de doutorado). Pontifícia Universidade Católica do Rio de Janeiro, Rio de Janeiro.

Cardoso, D., \& Amaral, H. F. (2000). O uso da simulação de Monte Carlo na elaboração do fluxo de caixa empresarial: uma proposta para quantificação das incertezas ambientais. In Anais do Encontro Nacional de Engenharia de Produção. São Paulo: ABEPRO.

Chen, H. L., Chen, W. T., \& Lin, Y. L. (2016). Earned value Project management: improving the predictive power of planned value. International Journal of Project Management, 34(1), 22-29. http://dx.doi.org/10.1016/j. ijproman.2015.09.008.

Christensen, D. S., \& Payne, K. I. (1992). Cost performance index stability - fact or fiction? Journal of Parametrics, 12(1), 27-40. http://dx.doi.org/10.1080/10157891.199 2.10462509 .

Colin, J., \& Vanhoucke, M. (2015). A comparison of the performance of various project control methods using Earned Value Management systems. Expert Systems with Applications, 42(6), 3159-3175. http://dx.doi. org/10.1016/j.eswa.2014.12.007.

Custer, K. (2008). Ten things you need to know about Earned Value Management (pp. 6-25). The Sea Ranch: Custer Consultants Inc.
Dinsmore, P. C., \& Rocha, L. (2012). Enterprise project governance: a guide to the successful management of projects across the organization. New York: AMACOM.

Doskočil, R. (2015). Fuzzy logic: an instrument for the evaluation of project status. Revista de Métodos Cuantitativos para La Economia y la Empresa, 19, 5-23.

Fleming, Q. W., \& Koppelman, J. M. (2010). Earned value project management (4th ed.). Newton Square: Project Management Institute.

Giacometti, R. A., Silva, C. E. S., Souza, H. J. C., Marins, F. A. S., \& Silva, E. R. S. (2007). Aplicação do earned value em projetos complexos - um estudo de caso na EMBRAER. Gestão \& Produção, 14(3), 595-607. http://dx.doi.org/10.1590/S0104-530X2007000300013.

Grey, S. (1995). Pratical risk assessment for project management. West Sussex: John Wiley \& Sons.

Henderson, K., \& Zwikael, O. (2008). Does project performance stability exist? A re-exanimation of CPI and evaluation of SPI(t) stability. Crosstalk, 4(21), 7-13.

Henriques, A. P. (2008). Metodologia de gestão integrada de prazos e custos: aplicação da metodologia Earned Value Management (Dissertação de mestrado). Instituto Superior Técnico, Universidade Técnica de Lisboa, Lisboa.

Kerkhove, L. P., \& Vanhoucke, M. (2017). Extensions of Earned Value Management: using the earned incentive metric to improve signal quality. International Journal of Project Management, 35(2), 148-168. http://dx.doi. org/10.1016/j.ijproman.2016.10.014.

Kerzner, H. (2014). Project management - best practices: achieving global excellence (3rd ed.). Hoboken: John Wiley \& Sons. http://dx.doi.org/10.1002/9781118835531.

Kim, B.-C. (2016). Probabilistic evaluation of cost performance stability in Earned Value Management. Journal of Management Engineering, 32(1), 1-13. http:// dx.doi.org/10.1061/(ASCE)ME.1943-5479.0000383.

Kim, E. H., Wells, W. G., Jr., \& Duffey, M. R. (2003). A model for effective implementation of earned value management methodology. International Journal of Project Management, 21(5), 375-382. http://dx.doi. org/10.1016/S0263-7863(02)00049-2.

Koning, P., \& Vanhoucke, M. (2016). Stability of earned value management: do projects characteristics influence the stability moment of the cost and schedule performance index. Journal of Modern Project Management, 4, 9-25.

Lipke, W. (2003). Schedule is different. The measurable news. Reston: CPM.

Lipke, W. (2011). Earned schedule application to small projects. PM World Today, 13, 1-12.

Lipke, W., Zwikael, O., Henderson, K., \& Anbari, F. (2009). Prediction of project outcome: the application of statistical methods to earned value management and earned schedule performance indexes. International 
Journal of Project Management, 27(4), 400-407. http:// dx.doi.org/10.1016/j.ijproman.2008.02.009.

Martins, E. (2010). Contabilidade de custos (10. ed.). São Paulo: Atlas.

Martins, R., Jr. (2006). Análise quantitativa de risco baseado no Método de Monte Carlo: abordagem PMBOK. In Anais do 1o Congresso Brasileiro de Gerenciamento de Projetos. Florianópolis: PMI.

Mattos, A. D. (2010). Planejamento e controle de obras. São Paulo: Pini.

Meredith, J. R., Mantel, S. J., \& Shafer, S. M. (2014). Project management: a managerial approach (9th ed.). Hoboken: John Wiley \& Sons.

Metropolis, N., \& Ulam, S. (1949). The Monte Carlo method. Journal of the American Statistical Association, 44(247), 335-341. http://dx.doi.org/10.1080/01621459 .1949.10483310. PMid:18139350.

National Defense Industrial Association - NDIA. (2015). Earned value management systems application guide. Arlington: NDIA.

Oliveira, R. C. F. (2003). Gerenciamento de projetos $e$ a aplicação da análise de Earned Value em grandes projetos. (Dissertação de mestrado). Escola Politécnica, Universidade de São Paulo, São Paulo.

Payne, K. I. (1990). An investigation of the stability of the cost performance index (Master thesis). School of Systems and Logistics, Air Force Institute of Technology, Ohio.

Prado, D. (2003). Gerenciamento de projetos nas organizações (2. ed.). Belo Horizonte: EDG.

Project Management Institute - PMI. (2013). Conjunto de conhecimentos em gerenciamento de projetos (PMBOK) (5. ed.). Newtown Square: Project Management Institute Inc.
Raby, M. (2000). Project management via earned value. MCB University Press, 49(1), 6-9.

Rovai, R. L., \& Toledo, N. N. (2002). Avaliação de performance de projetos através do Earned Value Management System. In Anais do Encontro Nacional de Engenharia de Produção (pp. 1-22). Curitiba: ABEPRO.

Schuyler, J. R. (2016). Risk and decision analysis in projects (3. ed.). Aurora: Planning Press.

Silva, C. N., Sampaio, V. R., \& Cândido, L. F. (2014). Análise de um modelo de medição de desempenho em projetos de construção. In Congresso Brasileiro de Engenharia de Produção (pp. 1-4), Ponta Grossa: CONBREPRO.

Slack, N., Chambers, S., \& Johnston, R. (2007). Administração da produção (3. ed.). São Paulo: Atlas.

Sobol', I. M. (1994). A primer for the Monte Carlo method. Boca Raton: CRC Press.

Vargas, R. V. (2004). Earned value probabilistic forecasting using Monte Carlo simulation. In Proceedings of the Transactions of the Association for the Advancement of Cost Engeneering. USA: AACE.

Vose, D. (2008). Risk analysis: a quantitative guide (3rd ed.). West Sussex: John Wiley \& Sons, LTD.

Willems, L. L., \& Vanhoucke, M. (2015). Classification of articles and journals on project control and earned value management. International Journal of Project Management, 33(7), 1610-1634. http://dx.doi.org/10.1016/j. ijproman.2015.06.003.

Yin, R. K. (2001). Estudo de caso: planejamento e métodos (2. ed.). Porto Alegre: Bookman.

Zwikael, O., Globerson, S., \& Raz, T. (2000). Evaluation of models for forecasting the final cost of a project. Project Management Journal, 31(1), 53-57. http:// dx.doi.org/10.1177/875697280003100108. 